\title{
CARACTERIZACIÓN LINGÜÍSTICA DE LOS PERSONAJES Y POLIFONIAA TEXTUAL EN EL LIBRO DE BUEN AMOR*
}

José Luis Girón Alconchel

U.N.E.D.

El poner en boca de los personajes de una narración determinadas variedades diatópicas, diastráticas, diafásicas y diacrónicas que contrastan con la variedad fundamental empleada por el narrador es un buen método para resaltar sus tipos o figuras, es decir, para caracterizarlos lingüisticamente. El procedimiento adquiere una gran importancia, como se sabe, en la novela realista; $y$ los estudios estilísticos lo han analizado más de una vez, sobre todo, en novelas modernas. En el Libro de Buen Amor este asunto no se ha estudiado monográficamente, aunque no faltan indicaciones. En el estudio de M. R. Lida sobre el estilo de Juan Ruiz - estudio todavía esencial, según Deyermond- se afirma que el gran valor del libro consiste en la elevación del lenguaje popular a categoria artística, patente sobre todo en los diálogos ' Al estudiar la apócope de la vocal en castellano antiguo, R. Lapesa señala que el Arcipreste emplea las formas consideradas ya populares e incluso vulgares en su época para caracterizar el habla rústica de las serranas ${ }^{2}$. En fin, en la edición del Libro de Buen Amor de J. Corominas existe un abundantísimo material, en la introducción y en las notas, que pone de manifiesto la extraordinaria diferenciación interna de la lengua de J. R. En este punto la edición de Corominas ha merecido el elogio de una crítica tan minuciosa y documentada como M. Morreale. Aunque algunos casos concretos se puedan discutir e incluso rebatir, no cabe duda de que Corominas ha enriquecido la visión histórica de la lengua del texto al destacar su polimor-

* Este trabajo fue leido como comunicación en el XV Simposio de la Sociedad Española de Lingüistica: Córdoba, diciembre de 1985.

1 Cf. M. Rosa Lida de Malkiel: Juan Ruiz. Selección del Libro de Buen Amor y estudios críticos, Buenos Aires, EUDEBA, 1973; el juicio de A. D. Deyermnond, en "El "Libro de Buen Amor" y la poesía del siglo XIV", en F. Rico (director): Historia y crítica de la literatura española, I. Edad Media (al cuidado de A. D. Deyermond), Barcelona, Editorial Crítica, 1980.

${ }^{2}$ R. Lapesa: «La apócope de la vocal en castellano antiguo. Intento de explicación histórica» y «De nuevo sobre la apócope vocálica en castellano medieval», ahora en Estudios de historia lingüitica española, Madrid, Paraninfo, 1985, pp. 167-197 y 198-208: 194 y 207. 
firmo, recoger sus variedades coloquiales y admitir un gran número de vulgarismos, generalmente con el apoyo del manuscrito G. ${ }^{3}$.

La misma complejidad y riqueza de esta lengua, junto con el afán del autor por exhibirlas y los arduos problemas de la tradición manuscrita hacen sumamente dificil un trabajo de esta índole. A pesar de ello, no es menos cierto que el Libro de Buen Amor, considerado como discurso, muestra un claro carácter "polifónico", en el sentido bajtiniano del término, observación que no se le ha pasado a un novelista y crítico de la experiencia de J. Goytisolo ${ }^{4}$. Basta reparar en los contactos de lenguas -latín y árabe con el castellano- o en la pluralidad de registros que se descubren aquí y allí para corroborar esta impresión. Por eso extraña que en monografias más recientes no se haya planteado este problema. En el libro de A. N. Zahareas, por ejemplo, lo más cercano a la cuestión es un epígrafe en el que se estudia "Trotaconventos in her Expressions». El autor presenta una lista de comentarios de la Vieja que reflejan algunos de los rasgos importantes de su carácter ${ }^{5}$. Pero no se analiza la lengua del personaje, sino el contenido semántico de algunos de sus enunciados. En el estudio de C. Gariano se señala la caracterización del personaje realizada por el narrador; pero no se aborda el tema de la caracterización lingüística. En este punto se repiten las observaciones sobre el popularismo y coloquialismo, ya conocidas desde M. R. Lida; y sólo muy de pasada se alude a lo que aquí nos interesa: a propósito de los versos «cuidándola yo aver entre las ben(e)ditas/dávale de mis donas...» (c.171), comenta Gariano: «una simple palabra popular (bendito) confiere un tono de conversación entre poeta y lector a lo que parace ser un giro meditado a solas» ${ }^{6}$.

$Y$, sin embargo, la investigación de las variedades internas de la lengua de J. R. y de su función en el discurso ofrece posibilidades muy probechosas

3 J. Corominas (ed.): J. R. Arcipreste de Hita, Libro de Buen Amor, Madrid, Gredos, 1967; M. Morreale: «Más apuntes para un comentario literal del «LBA» sugeridos por la edición de Joan Corominas", en Hispanic Review, 37 y 39 (1969-1971), pp. 131-163 y 271-313: 132-133.

4 Compárese: «No conozco en ésta [en "nuestra literatura»]-tanto desde el punto de vista del léxico como del de la estructura, prosodia y sintaxis-obra tan sorprendente, múltiple, polimorfa como la del Arcipreste. La realidad textual que nos brinda no es bidimensional ni uniforme: presenta quiebras, desniveles, rupturas, tensiones centrífugas, transmutación de voces; en una palabra, polifonia» (Juan Goytisolo: "El Arcipreste de Hita y nosotros", en J. Benet et alii: Edad Media y Literatura contemporánea, Madrid, Ed. Trieste, 1985: pp. 21-31:27). He tratado el aspecto "polifónico" del "LBA" en "Sobre la lengua de Juan Ruiz. Enunciación y estilo épico en el "LBA», en Epos, 1(1984), pp. 35-70; y en «Enunciación y estilo épico en el Libro de Buen Amor: algunos aspectos de la polifonía textual:", Comunicación leída en el I Coloquio Luso-Español de Semiótica, Porto, noviembre, 1985 (actualmente en prensa, en las Actas de dicho Coloquio). Por otra parte, estos dos trabajos se continúan y forman un todo. Véase ahora también, G. Reyes: Polifonia textual. La citación en el relato literario. Madrid, Gredos, 1984.

5 A. N. Zahareas: The Art of Juan Ruiz, Archpriest of Hita, Madrid, 1965, pp. 163-168.

6 El mundo poético de Juan Ruiz, Madrid, Gredos, 1974, p. 157. 
para comprender algunos aspectos de la obra todavía oscuros y para conocer mejor la historia de nuestra lengua literaria.

Señalemos, en primer lugar, la cuestión del género literario. D. Alonso valoró hace algún tiempo la lengua hablada que reproducen el Libro de Buen Amor y el Corbacho. Este elemento sociolingüístico es lo que convierte a nuestras dos obras medievales en genuinos precedentes del LazariIlo y el Quijote. Vale la pena reproducir sus palabras:

Son las obras de nuestros dos Arciprestes libros bien curiosos: por una parte, sumamente toscos, desordenados, de una inmadurez verdaderamente medieval, con una excesiva abundancia de materiales, una falta evidente de sentido de la medida; pero, desde otras perspectivas, cuán alegres y certeros de lenguaje, cómo apuran las posibilidades de la expresión humana, cómo transparentan los matices y los movimientos anímicos, los móviles de la intención, y los secretos hitos adonde ésta se dirige. Y todo se produce, mucho más que por las explicaciones del autor, por las palabras-variadas, en borbotón, libérrimas y al par ligadas a los giros más comunes-que pone en boca de sus criaturas ${ }^{7}$.

Nótese, de pasada, la definición de caracterización lingüistica de los personajes, a la que me atengo. Y nótese, además, la coincidencia del maestro español con las ideas de Bajtín sobre el nacimiento de la novela europea en el siglo XIV. Para el lingüista ruso uno de los aspectos que presenta la creación del género en esa época es precisamente la incorporación del plurilingüismo al discurso narrativo".

Más recientemente $F$. $R$. Adrados ha sugerido que la novela realista latina - y más concretamente la Vida de Esopo- pudo servir de modelo, como género literario, para el Libro de Buen Amor. Pues bien, según el mismo Adrados, esa novela se distingue por su «carácter popular y aun vulgar, que llega a la chocarrería en el lenguaje y estilo»"

Por lo que respecta a las posibilidades que la perspectiva de análisis que presento ofrece para un mejor conocimiento de la historia de la lengua literaria, consignemos sólo un par de observaciones. La oralidad de los textos medievales determina el carácter polifónico de las variedades internas de la lengua; permite que estos discursos sociales -en término de Bajtín-actúen como elementos modalizadores del discurso que los estiliza y reproduce. De este modo, las variedades internas se convierten en palabra representada en el discurso, en citas, en marcas de una enunciación mencionada ${ }^{10}$.

7 "El Arcipreste de Talavera a medio camino entre moralista y novelista" Obras Completas, II. Madrid, Gredos, 1973, pp. 443-452: 444

${ }^{8}$ Apud J. Talens: La escritura como teatralidad. Acerca de Juan Ruiz, Santillana y elmarco narrativo en la novela corta del siglo xvIII. Valencia, 1977, p. 81.

9 "El Libro de Buen Amor y la Vida de Esopo", en Serta Philologica F. Lázaro Carreter, II, Madrid. Cátedra, 1983, pp. 427-34: 429.

10 He desarrollado estos conceptos en mis dos trabajos citados en la n. 4. 
Resulta sorprendente comprobar que algunas anotaciones de Corominas siguen ya esta pista. Al final del episodio de Garoza, en un pasaje narrativo, aparecen estas coplas que el editor pone entre comillas:

¿Valme, Santa Maria!, mis manos me aprieto;

¿quién dio a blanca rosa ábito, velo prieto?

Más valdrié a la fermosa tener fijos e nieto

que atal velo prieto nin que ábitos fiento.

Pero que sea errança contra Nuestro Señor

pecado de monja a omne doñeador,

iay Dios!, ie yo lo fuesse aqueste pecador,

que feziés penitencia deste fecho error!

$(1500-1501)$

Corominas justifica en nota el empleo de las comillas con el siguiente comentario:

Estas dos estrofas son evidentemente palabras que el autor pone en boca del protagonista, como pronunciadas en este momento: nótese el optativo fuesse ( $1501 \mathrm{c}$ ) proyectado todavia hacia un futuro incierto, $y$ la frase coloquial mis manos me aprieto, que no convendría en boca de un moralista (menos todavía los versos $1501 c d$ ) (p. 556, n.).

He aquí un ejemplo de polifonia textual. La recitación oral -el papel que el texto representa en el escenario, como dice gráficamente P. Zumthor ${ }^{11}-$ la hace posible. Veamos otro ejemplo en el que la polifonia textual funciona como caracterización del personaje, apoyada en la oralidad del texto. Al estudiar el articulo ante posesivo en la obra del Arcipreste, dice Lapesa que éste elige tal variedad -frente a la opción del posesivo sin artículo- cuando quiere expresar "emoción, reverencia o halago» ${ }^{12}$. Pues bien, si nos fijamos en los ejemplos que el mismo Lapesa aporta, descubriremos que los enunciados en que aparece la secuencia articulo+posesivo son palabras de los personajes, no del narrador. La variedad estilística funciona como forma lingüística caracterizadora. En un discurso de don Melón a la Vieja alcahueta, que ocupa tres estrofas (701-703), se observa que el hablante emplea el posesivo sin artículo al comienzo y al final, sobre todo para referirse a realidades poseídas por él mismo, y en una sola ocasión cuando el poseedor es

11 Véase P. Zumthor: Essai de poétique médièvale, París, Editions du Seuil, 1972.

12 "Sobre el articulo ante posesivo en castellano antiguo", Sprache und Geschichte. Festschrift für Harri Meier, München, 1971, pp. 227-296:287. 
su interlocutora. Pero en la parte central del discurso -c. 702-, cuando el hablante descubre su principal propósito, no vacila en emplear la construcción enfática: por la vuestra buena fama yo he por vos enbiado $702 \mathrm{~d}$. El significado estilístico de la construcción experimenta un nuevo cifrado en el texto de J. R.: sirve para caracterizar al personaje y la estrategia de su discurso. Curiosamente la construcción enfática se sitúa en el verso cuarto de la estrofa, verso en el que, como se sabe, se suele dar una concentración de rasgos significativos. Una historia de la lengua literaria o Poética diacrónica debe dar cuenta de este doble cifrado de las formas lingüísticas, como ha señalado hace poco F. Lázaro Carreter ${ }^{13}$.

Finalmente, el estudio de las variedades internas de la lengua y de su función discursiva debe relacionarse con la teoría del decoro poético y de los tres estilos (sublime, medio y bajo). Más de una vez se ha señalado la importancia de las poéticas medievales en la composición del Libro de Buen Amor; pero nadie, que yo sepa, se ha detenido en este punto concreto. Y, sin embargo, en la fundamental obra de E. Faral se registra esta observación: en el sistema escolar de los siglos XII y XIII se produce un cambio en la valoración de los tres estilos; consiste en que éstos se convierten en un asunto de dignidad social; es la calidad de la persona -dice Faral-, y no la de la elocución, la que proporciona el principio de la clasificación estilística. Y este cambio afecta tanto a la literatura latina cuanto a la escrita en lengua vulgar, añade ${ }^{14}$. Creo que nuestro Libro de Buen Amor participa en esta nueva valoración de la técnica poética. De hecho son las variedades vulgares y coloquiales las que presentan un mayor rendimiento funcional como formas caracterizadoras. Les siguen las formas del tratamiento, que por su propia naturaleza significan las relaciones sociales establecidas en la comunidad.

Analizaremos ahora brevemente, y con los presupuestos reseñados, la función discursiva de algunas de estas formas, pertenecientes a los planos fónico, gramatical y léxico.

En primer lugar, fijémonos en el paso de /F-/ latina al sonido aspirado castellano [h-]. Como se sabe, a lo largo del siglo XIV se propaga esta pronunciación norteña, aunque sin alcanzar mucho éxito en la lengua literaria. Lo cual nos permite suponer que se la consideraba popular, cuando no vulgar o rústica. Pues bien, esta pronunciación suele ponerse en boca de las serranas y de Trotaconventos. Fijándonos en este último personaje, la encontramos en discursos dirigidos al protagonista (aqueste mi harnero 718d, ponen toda su hemencia $1338 \mathrm{~d}$ ); cuando se dirige a Endrina, alterna la pro-

13 "Consideraciones sobre la historia de la lengua literaria", en M. Alvar (coord.): Actas delll Simposio Internacional de la Lengua Española (1981), Ediciones del Excmo. Cabildo Insular de Gran Canaria, 1984, pp. 525-541.

14 Les Arts poétiques du xII' et du xIIr siécle. Recherches et documents surla technique littéraire du Moyen Age [1924], Slatkine, Genéve / Champion, París, 1982, pp. 88 y 89. 
nunciación normativa y la popular: hado bueno que vos tienen vuestras $\mathrm{fa}$ das fadado 716d. En este último verso el manuscrito único es $\mathrm{G}$; en los dos anteriores la aspiración se documenta en $\mathrm{G}$ y $\mathrm{T}$, mientras que $\mathrm{S}$ lee farnero y femençia. Por lo demás, el verso en que se halla el fenómeno es siempre el cuarto de la respectiva cuarteta. Estos datos permiten considerar la aspiración del /F-/ como la manifestación de un discurso social, estilizado y exhibido en el discurso literario, como una cita que caracteriza el habla de estos personajes con una nota de popularismo.

La misma función discursiva se puede asignar a una variedad morfológica: las segundas personas verbales en -és y -ás ${ }^{15}$. En la época del Arcipreste son, sin duda, vulgarismos de dificil aceptación en la lengua literaria. En el Libro de Buen Amor aparecen cinco casos seguros, atestiguados por un manuscrito o más de uno; de ellos tres corresponden a -és por -edes, y dos a -ás por -ades. Hay, además, otros dos casos discutibles, no documentados en los manuscritos, pero interpretables como formas contractas por motivos métricos o semánticos; uno corresponde a -ás y otro a -és. En total siete casos de este vulgarismo morfológico. Cinco de los cuales están puestos en boca de Trotaconventos; uno se asigna a Melón y el otro a un animal (la puerca) de una fábula contada por Endrina. En cuatro ocasiones el vulgarismo se halla en el verso cuarto de la estrofa. No ofrecen ninguna dificultad el irés $1451 \mathrm{~d}$ y el andarés $1332 \mathrm{~d}$ con que Trotaconventos se refiere a Garoza y al Arcipreste protagonista, respectivamente; están documentados en S y G. Teniendo a Endrina como interlocutora, la Vieja dice trayés $832 \mathrm{~d}$, según $\mathrm{G}$, y traedes, según $\mathrm{S}$. Los editores se han inclinado por la forma culta. Cuando Trotaconventos reprende al Arcipreste por los apodos, el único manuscrito S lee: "Nunca digas nonbre malo nin de fealdat, / llamat me buen amor..." 932a. Por razones de ritmo Corominas interpreta digás, desechando una ruptura del tratamiento y adhiriéndose al vulgarismo de la segunda persona. En cambio, Joset ${ }^{16}$ admite la enmienda, digades, de Cejador. Finalmente, dirigiéndose a Garoza dice Trotacoventos: dexar plazer e viçio e lazerịa queredes 1386b; esto es lo que se lee en los manuscritos, aunque para entenderlo haya que interpretar, con cierta violencia, queredes dexar plazer e vicio e queredes lazeria. El sentido aboga por la enmienda dexás; la alternancia de esta forma vulgar con la culta queredes podría explicarse por la rima, que exige esta última; o por el mismo motivo por el que, en un verso ya visto, alternan /F-/ y aspiración en un discurso de la misma vieja a otra dama, a Endrina. Los editores no llegan a enmendar, aunque Corominas apunta la verosimilitud de la variedad vulgar. En el discurso de Melón a Endrina, el único manuscrito $\mathrm{G}$ lee querriedes $672 \mathrm{~d}$; pero Corominas prefiere el vulgarismo querriés por razones métricas. Por último, en la fábula mencionada

15 Cf. R. Lapesa: "Las formas verbales de segunda persona y los origenes del "voseo"», en Actas del III Congreso Internacional de Hispanistas, México, 1970, pp. 519-531.

16 J. Joset (ed.): JR., Libro de Buen Amor, Madrid, Espasa-Calpe, 1981, Clás. Cast., 2 vol. 
antes, el animal que habla dice ayás 777a, según el único manuscrito $\mathrm{S}$. En cambio, los editores optan por la enmienda ayades. Como vemos, los editores siguen diversos criterios, que a veces chocan entre sí. A pesar de todo, parece segura la atribución del vulgarismo caracterizador al habla de Trotaconventos, y es muy probable en los otros casos.

Como variedad sintáctica abundan en el Libro de Buen Amor las construcciones claramente coloquiales. Seleccionando un poco al azar, encontramos un nominativus pendens coloquial en el habla de Trotaconventos: el mormullo e el roido, que lo digan non ay quien 851 b. Otra construcción de "tono típicamente coloquial» ${ }^{17}$ por el empleo del posesivo es bien cabe su açunbre e más una meaja 1207c; es discurso del narrador en la pelea paródica de Carnal y Cuaresma; el verso se encuadra en la descripción irónica de la huida de esta última, de modo que el coloquialismo sintáctico se integra en el humorismo del contexto. En otros casos la variedad coloquial caracteriza el habla de personajes de una fábula contada por un personaje del relato principal; sirve, pues, a la distinción de los niveles semiológicos de la narración. Así, el gerundio con valor de imperativo ( $i$ Andando efablando, amigo! $1465 \mathrm{~d}$ ) o la exclamación (ial diablo catedes vos el polso! 1419c), puestos respectivamente en boca del diablo y de la zorra en fábulas contadas por $\mathrm{Ga}$ roza.

Las variedades del nivel léxico son muy frecuentes en el Libro de Buen Amor: arcaísmos, cultismos, tecnicismos (jurídicos, escolásticos...), lexemas caracteristicos de determinados géneros literarios, como la épica y la poesía cortés, etc. Apuntaré sólo un par de casos que pueden interpretarse. como variedades diastráticas caracterizadoras. En la aventura de la serrana de Malangosto el narrador protagonista dice cofonda $963 \mathrm{~b}$, según $\mathrm{G}$, mientras que S lee confonda. Según M. Morreale (1979:132), las dos formas «coexisten en el siglo XIII; cofonder se transmitió por vía popular, con la ac. de "echar a perder, arruinar", sin poderse conmutar con la forma culta»" ${ }^{18}$. Una vez más es preferible la lectura avulgarada o popular de $G$ por su valor caracterizador. Algo parecido ocurre con el aponf̧ñar 1352d usado por Garoza al contar una fábula. La variedad autorizada literariamente en la época era ponzoñar: así, en don Juan Manuel, en la Conquista de Ultramary hasta en Nebrija (Cor., 508, n.). Sin embargo, los tres manuscritos optan por la forma nueva: aponfoñar en G y T; empoçoñar en S.

Por último, observemos cómo un repertorio sociolingüístico -el sistema de tratamientos- se emplea en el Libro de Buen Amor con intención caracterizadora. Es bien sabido que en los siglos XII y XIII el tuteo es general en el discurso de la "gente llana», mientras que el tratamiento normal en los

17 M. Morreale: "Sobre la reciente edición del "LBA" por J. Joset para "Clásicos CasteIlanos"”, Thesaurus, 34 (1979), pp. 94-137: 120 y 125.

18 Id.: p. 132. 
estamentos superiores es vos. R. Lapesa ha descrito, en sus líneas generales, la situación en el siglo XIV y en el Libro de Buen Amor; dice que esta obra

muestra la penetración del vos en los ambientes burgueses: de vos se tratan don Melón y doña Endrina, la viudita y Trotaconventos, la buhona y el galán, don Pitas Pajas y su mujer. Pero tú seguía vivo en la conversación con inferiores o con iguales de gran confianza, según testimonio del Arcipreste de Talavera un siglo más tarde ${ }^{19}$.

Esta autorizada visión de conjunto nos permite descubrir la función caracterizadora que, en algunas excepciones, desempeñan las formas de tratamiento en el Libro de Buen Amor. Doña Endrina trata de vos a Trotaconventos sólo hasta un determinado momento del relato. En el último verso de la c. 742, al concluir un parlamento, ya la viudita insinúa el tuteo; y, un poco más adelante, en la 764 , se consuma definitivamente el cambio de tratamiento:

\footnotetext{
Respondió Doña Endrina: "Dexat, non osaria fazer lo que $m$ ' dezides nin lo que él querria: non me digas agora más d'esa ledania, non me afinques tanto luego el primero dia".
}

A partir de este momento la dama tutea sistemáticamente a la alcahueta. Como dice Corominas, el tuteo es aquí señal de los progresos de la vieja en su trato con Endrina $(290, n$.), o sea, elemento caracterizador del habla y de la conducta social que el habla significa. También la monja Garoza tutea sistemáticamente, y desde el principio, a Trotaconventos; ésta, en cambio, le habla de vos. Aqui el tuteo, como forma caracterizadora, está en función de la coherencia textual. Al comienzo de la aventura, como se recordará, el narrador nos informa que la vieja había servido antes a la monja (1344a). Las formas de tratamiento caracterizan también el cambio en las relaciones del protagonista con la alcahueta. Mientras que durante todo el episodio de Endrina la trata de vos-llamándola madrey señora-, después de la pelea que ambos mantienen por los apodos de la alcahueta, la tutea sin excepciones hasta el final de la obra. Trotaconventos, en cambio, lo sigue tratando de vos. El Libro de Buen Amor documenta, pues, el tuteo dispensado a inferiores o a iguales de gran confianza, al tiempo que este uso sociolingüístico caracteriza a los personajes del relato.

También documenta nuestra obra el cambio inverso, de tú a vos. Los

19 «Personas gramaticales y tratamientos en español», Rev. de la Universidad de Madrid, 74 (1970), pp. 141-167: 145 . 
textos del siglo XVI, que Lapesa cita, evidencian que "tratar de vos a quien de ordinario se tuteaba era muestra de irritación ${ }^{20}$ ». En el Libro de Buen Amor este paso del tú al vos ocurre en una sola ocasión, en el ejemplo del león y del mur (cs. 1425 y ss.), contado por Trotaconventos a Garoza. El ratón tutea al león, cuando éste lo puede matar (c. 146); pero cuando está en condiciones de superioridad lo trata de vos (cs. 1431-32). El tratamiento caracteriza la actitud irónica del personaje animal, sin duda, trasunto de la ironía de la Vieja a quien se atribuye la narración de la fábula.

Desde la perspectiva del análisis del discurso, la complejidad interna de la lengua de J. R. no es ni simple gusto por el polimorfismo y la sinonimia ni, menos aún, inmadurez caótica o tosquedad; antes bien, es una heterogeneidad organizada, una exhibición del diasistema estilizado. De ahí su carácter polifónico. Las variedades diastráticas y el uso del sistema de tratamientos ejemplifican una intención caracterizadora, guiada por principios artísticos inmanentes. Aunque no podamos elaborar nunca una sociolingüistica del castellano real del siglo XIV, tenemos en el Libro de Buen Amor una muestra "cosificada" -sacada de su contexto genuino- de lo que pudieron ser algunos de los más importantes discursos sociales de aquella época. Los conocimientos de Poética -y concretamente, la nueva valoración de la teoría del decoro y de los tres estilos-hubieron de alertar al fino escritor que era J. R.: supo sacar el máximo provecho de una lengua que, heredera de grandes vacilaciones todavía no resueltas y sometida a la presión de corrientes innovadoras, se abría camino lentamente hacia su regularización. 